\title{
Using the Inverse Method to Investigate Flow Models for Mixed Convection of Annular Finned Tube Heat Exchanger
}

\author{
Han-Taw Chen \\ Department of Mechanical Engineering, National Cheng Kung University, Tainan, Taiwan \\ Cheng-Hui You \\ Department of Mechanical Engineering, National Cheng Kung University, Tainan, Taiwan \\ Wei-Lun Hsu \\ Department of Mechanical Engineering, National Cheng Kung University, Tainan, Taiwan \\ Jiang-Ren Chang \\ Department of Systems Engineering \& Naval Architecture, National Taiwan Ocean University, Keelung, Taiwan, \\ cjr@mail.ntou.edu.tw
}

Follow this and additional works at: https://jmstt.ntou.edu.tw/journal

Part of the Fresh Water Studies Commons, Marine Biology Commons, Ocean Engineering Commons, Oceanography Commons, and the Other Oceanography and Atmospheric Sciences and Meteorology Commons

\section{Recommended Citation}

Chen, Han-Taw; You, Cheng-Hui; Hsu, Wei-Lun; and Chang, Jiang-Ren (2021) "Using the Inverse Method to Investigate Flow Models for Mixed Convection of Annular Finned Tube Heat Exchanger," Journal of Marine Science and Technology: Vol. 29: Iss. 5, Article 6.

DOI: $10.51400 / 2709-6998.2467$

Available at: https://jmstt.ntou.edu.tw/journal/vol29/iss5/6

This Research Article is brought to you for free and open access by Journal of Marine Science and Technology. It has been accepted for inclusion in Journal of Marine Science and Technology by an authorized editor of Journal of Marine Science and Technology. 


\title{
Using the Inverse Method to Investigate Flow Models for Mixed Convection of Annular Finned Tube Heat Exchanger
}

\author{
Han-Taw Chen ${ }^{a}$, Cheng-Hui You ${ }^{a}$, Wei-Lun Hsu ${ }^{a}$, Jiang-Ren Chang ${ }^{b, c, *}$ \\ ${ }^{a}$ Department of Mechanical Engineering, National Cheng Kung University, Tainan 701, Taiwan \\ ${ }^{\mathrm{b}}$ Department of Systems Engineering \& Naval Architecture, National Taiwan Ocean University, 2, Pei-Ning Road., Keelung 20224, \\ Taiwan \\ ${ }^{\mathrm{c}}$ Maritime Training Center, Department of Shipping Technology, National Kaohsiung University of Science and Technology, Kaohsiung \\ 80543, Taiwan
}

\begin{abstract}
The inverse heat conduction method (IHCM) and three-dimensional (3D) computational fluid dynamic (CFD) in combination with $T_{k}^{m}$ are used to select the appropriate flow model and near-wall treatment for the mixed convection of the annular finned tube heat exchanger. Thus, the numerical results obtained by all $k-\epsilon$ models and near-wall treatments are yielded for $4 \mathrm{~m} / \mathrm{s} \leq V_{a} \leq 5 \mathrm{~m} / \mathrm{s}$. First, IHCM combined with $T_{k}^{m}$ is applied to estimate $\bar{h}$ and $Q$ values. The obtained estimates of $\bar{h}$ and $Q$ are used as reference values for CFD. The results show that the $T_{k}$ and $\bar{h}$ results obtained by the standard (STD) $k-\epsilon$ model with the standard wall function (SWF) are closer to $T_{k}^{m}$ and the estimates of $\bar{h}$ than those by the realizable (REAL) and RNG $k-\epsilon$ models with various wall functions for $V_{a}$ of $4-5 \mathrm{~m} / \mathrm{s}$. The $\bar{h}$ value obtained from the STD $k-\epsilon$ model with SWF, $V_{a}=5 \mathrm{~m} / \mathrm{s}$ and $S=15 \mathrm{~mm}$ may be 1.14 times that of the RNG $k-\epsilon$ model and 0.48 times that of the REAL $k$ - $\epsilon$ model. The $\bar{h}$ value of the RNG $k-\epsilon$ model with SWF is about 1.6-1.7 times that with EWT for $S=5$ mm and $V_{a}=4 \mathrm{~m} / \mathrm{s}$ and $5 \mathrm{~m} / \mathrm{s}$. These differences mean that the appropriate flow model needs to be varied with $V_{a}$ to obtain more accurate numerical results. The $y^{+}$of RNG and STD $k-\epsilon$ models does not exceed 3 . However, the $y^{+}$of the REAL $k-\epsilon$ model exceeds 6 . To our best knowledge, no studies have explored this issue and the present investigation tries to bridge this gap.
\end{abstract}

Keywords: CFD and IHCM, Mixed convection, Flow model, Heat exchanger

\section{Introduction}

$\mathrm{T}$ he plate-finned tube heat exchangers are often used in industry. As shown in Refs. $[1-3,5,6,8,10-16,18-23]$, complex 3D fluid flow and heat transfer characteristics can be found in these heat exchangers. The flow phenomenon is strongly influenced by tubes and fins. The flow is accelerated around the horizontal tube in cross flow. The boundary layer begins to develop in front of the tube and gradually grows along the flow direction. The low-speed region appears in the wake region behind the tube. Therefore, the heat transfer coefficient on the fins is non-uniformly distributed. The CFD numerical results obtained should be compared with $T_{k}^{m}$ and $h(r, \theta)$ obtained by a more accurate correlation or IHCM to verify their accuracy in thermal engineering applications.

Mon and Gross [11] used the RNG $k-\epsilon$ model of FLUENT to study the effect of $S$ on the annular finned tube bundle for $R e$ of $8.6 \times 10^{3}-4.3 \times 10^{4}$. According to Mon and Gross [11] fluid flow within and outside the fins is considered to be laminar and turbulent, respectively. Yan et al. [22] applied the

Received 19 October 2020; revised 17 February 2021; accepted 17 June 2021.

Available online 18 November 2021.

* Corresponding author.

E-mail address: cjr@mail.ntou.edu.tw (J-R. Chang). 
multiple-relaxation-time based on lattice Boltzmann method to investigate the characteristic flow regions for three staggered stationary circular cylinders. Based on their numerical results, two characteristic steady flow regions are found, and the features of structure interaction and vortex shedding behind cylinders are specifically investigated. The onedimensional (1D) fin heat conduction equation (FHCE) is assumed in Refs. [11,22]. Xie et al. [21] applied the SIMPLE algorithm to study the 3D airside laminar heat transfer characteristics of platefinned tube heat exchangers with copper fins, larger copper tube diameters and Reynolds numbers of 1000-6000. However, the FHCE is not considered. Gherasim et al. [8] compared the numerical predictions of hydrodynamic and thermal fields obtained from two-equation turbulence models and laminar flow in two-channel plate heat exchangers with experimental data for Reynolds numbers $(R e)$ of 400-3000. The Nusselt number and friction coefficient, etc., are compared. Their comparisons show that the numerical results of the REAL $k-\epsilon$ model and non-equilibrium wall function (NEWF) are closer to the experimental data than the results from other flow models and various wall functions. The Nusselt number of the REAL $k-\epsilon$ model with EWT is greater than that with SWF for Re of 400-1400. The Nusselt number of the REAL $k-\epsilon$ model and NEWF is consistent with the experimental data for $R e$ of $400-800$ and deviates from the experimental values for $R e$ of 1000-1400. Salimipour [19] studied the 2D laminar mixed convection occurring from a horizontal cylinder using a cellvertex finite-volume scheme and IRK-SIMPLER for $R e=200$ and Prandtl number $(P r)$ of 0.71 . Nematic and Moghimi [13] applied nine different turbulence models to simulate a turbulent flow through a fourrow finned tube heat exchanger at $V_{a}=2 \mathrm{~m} / \mathrm{s}$. Laminar flow is considered to pass through the fins. The basic grid included 95,760 cells. This amount of cells guarantees that $y^{+}$value nowhere exceeds 7 . It then adapted for each method to reduce $\mathrm{y}^{+}$value to below three. It is observed from Table 2 in Ref. [22] that the Nusselt numbers of the STD, RNG and REAL $k-\epsilon$ models are consistent with the experimental results. However, the Nusselt number of the STD $k-\epsilon$ model is slightly smaller than that of the REAL and RNG $k-\epsilon$ models. Nematic et al. [16] used a CFD commercial software and ANSYS CFX to study the 3D laminar natural convection heat transfer of horizontal annular finned tubes in the range of $1.3<R a<2.7 \times 10^{4}$. According to the numerical flow visualization, a new modification of the Rayleigh number is proposed. Nematic et al. [15] also applied the numerical method in Ref. [16] to

\begin{tabular}{|c|c|}
\hline \multicolumn{2}{|c|}{ Nomenclature } \\
\hline$d_{0}$ & outer diameter of the circular tube, $\mathrm{mm}$ \\
\hline$D$ & outer diameter of the annular fins, $\mathrm{mm}$ \\
\hline$f$ & friction factor defined in Eq. (29) \\
\hline$[F]$ & forced matrix \\
\hline $\bar{h}$ & average heat transfer coefficient on fins $\left(\mathrm{W} / \mathrm{m}^{2} \mathrm{~K}\right)$ \\
\hline $\bar{h}_{b}$ & heat transfer coefficient at $T_{b}\left(\mathrm{~W} / \mathrm{m}^{2} \mathrm{~K}\right)$ \\
\hline$[K]$ & global conduction matrix \\
\hline$k_{a}$ & thermal conductivity of air $(\mathrm{W} / \mathrm{m} \mathrm{K})$ \\
\hline$k_{f}$ & thermal conductivity of fins (W/m K) \\
\hline$\ell_{r}, \ell_{\theta}$ & $\begin{array}{l}\text { distance between two adjacent nodes in the } r \text { and } \theta \\
\text { directions (m) }\end{array}$ \\
\hline$N$ & number of sub-fin regions \\
\hline$N_{r}, N_{\theta}, N_{z}$ & number of grid points in $r, \theta$ and $z$ directions \\
\hline & total number of grid points \\
\hline$N u_{d}$ & Nusselt number, $\mathrm{N} u_{d}=\bar{h} d_{0} / k_{a}$ \\
\hline$r, \theta, z$ & cylindrical coordinates \\
\hline$R e_{d}$ & Reynolds number, $\operatorname{Re}_{d}=V_{a} d_{0} / \nu$ \\
\hline$S$ & fin spacing $(\mathrm{mm})$ \\
\hline$T$ & fin temperature $(\mathrm{K})$ \\
\hline$T_{a}$ & air temperature $(\mathrm{K})$ \\
\hline$T_{b}$ & temperature at the fin base $(\mathrm{K})$ \\
\hline$T_{k}$ & $\begin{array}{l}\text { fin temperature at the } k \text { th measurement position } \\
(\mathrm{K})\end{array}$ \\
\hline$T_{k}^{n}$ & CFD numerical result of $T_{k}(\mathrm{~K})$ \\
\hline$T_{k}^{m}$ & experimental data of $T_{k}(\mathrm{~K})$ \\
\hline$t$ & fin thickness $(\mathrm{mm})$ \\
\hline$V_{a}$ & inlet speed $(\mathrm{m} / \mathrm{s})$ \\
\hline$y^{+}$ & dimensionless wall distance \\
\hline
\end{tabular}

obtain the numerical results of 3D laminar natural convection for horizontal annular elliptical finned tubes. Senapati et al. [20] used the algebraic multigrid solver of FLUENT 15 to investigate natural convection heat transfer from vertical cylinder with annular fins by varying the Rayleigh number $(R a)$ in both laminar $\left(10^{4}<\mathrm{Ra}<10^{8}\right)$ and turbulent $\left(10^{10}<R a<10^{12}\right)$ regimes. Nematic et al. [14] used the Fluent solver module ANSYS 19.1 combined with the transition SST (Shear stress transport) turbulence model to obtain the global heat transfer coefficient and pressure drop of the air-cooled fourrow finned-tube heat exchanger in the range of 3000 $<V_{\max } d_{0} / \nu<10,000$, where $V_{\max }$ is obtained from Eq. (16) in Ref. [14]. Both tubes and fins are made of aluminum. The $y^{+}$value in Ref. [14] is assumed to be less than three. Experimental data was then used to verify the numerical results obtained. The validated simulation tool is then used to perform model-based optimization of the fin shape. It is found in Refs. [8,11,13-16,19-22] that a specific flow model is applied to investigate various practical problems. The flow model used in Refs. [13-16] is different from that in Ref. [1-3]. Chen et al. [1-3,5,6] applied 3D CFD commercial software [7] in combination with the inverse results of $\bar{h}_{b}$ and $\bar{h}, T_{k}^{m}$ and various flow models to study the heat transfer 
characteristics of various types of plate-finned tube heat exchangers. The CFD results of $\bar{h}, Q$ and $T_{k}$ obtained agree with their corresponding inverse results and $T_{k}^{m}$, respectively. The assumption of grid independence may not be appropriate. In addition, the air velocity pattern of $V_{a}=3 \mathrm{~m} / \mathrm{s}$ and $S=5 \mathrm{~mm}$ obtained by Chen et al. [1] agrees with the experimental pattern in Ref. [18] for $R e_{d}=1785.67$ and 4657.46. The air temperature contours obtained by Chen et al. [1] are consistent with the temperature contours retrieved from the interferometric images in Ref. [12]. This implies that the results obtained by the hybrid method of CFD and IHCM combined with $T_{k}^{m}$ may warrant further verification. The accuracy of the CFD results obtained by a specific flow model, such as a laminar flow or STD $k-\epsilon$ model, may need to be carefully verified. Thus, the main goal of this study is to choose the appropriate $k-\epsilon$ model and near-wall treatment for the mixed convection of the annular finned tube heat exchanger with $V_{a}$ of $4-5 \mathrm{~m} / \mathrm{s}$. In other words, it remains to be seen whether the appropriate flow model and nearwall treatment should vary with $V_{a}$ to obtain more accurate numerical results.

\section{Inverse heat conduction method (IHCM)}

Figure 1 shows the physical geometry of the IHCM with $V_{a}$, measurement locations and sub-fin regions. The basic assumptions and experimental apparatus and methods can be found in Ref. [1]. The 2D steady-state FHCE and boundary conditions can be expressed as follows.

$$
\begin{aligned}
& \frac{\partial^{2} T}{\partial r^{2}}+\frac{1}{r} \frac{\partial T}{\partial r}+\frac{1}{r^{2}} \frac{\partial^{2} T}{\partial \theta^{2}}=\frac{2 h(r, \theta)}{t k_{f}}\left(T-T_{\infty}\right) \\
& T=T_{b} \quad \text { at } r=d_{0} / 2 \\
& \frac{\partial T}{\partial r}=0 \quad \text { at } r=D / 2 \\
& \partial \mathrm{T}(\mathrm{r}, 0) / \partial \theta=\partial T(r, 2 \pi) / \partial \theta
\end{aligned}
$$

and

$\mathrm{T}(\mathrm{r}, 0)=T(r, 2 \pi)$

where $d_{0}$ and $D$ are the outer diameters of the tube and fin, respectively. $h(r, \theta)$ is the heat transfer coefficient on fins. $T_{\infty}$ is the ambient temperature. $T_{b}$ is considered as tube temperature. The values of $\bar{h}_{b}$ and $\bar{h}$ can be estimated from Eqs. (1)-(5) based on $T_{k}^{m}$.

The finite difference form of Eq. (1) in the $k$ th subfin region is expressed as follows [1,2].

$$
\begin{aligned}
\frac{T_{i+1, j}-2 T_{i, j}+T_{i-1, j}}{\ell_{r}^{2}}+\frac{T_{i+1, j}-T_{i-1, j}}{2\left[R_{i}+(i-1) \ell_{r}\right] \ell_{r}}+\frac{T_{i, j+1}-2 T_{i, j}+T_{i, j-1}}{\left[R_{i}+(i-1) \ell_{r}\right]^{2} \ell_{\theta}^{2}} \\
=\frac{2 \bar{h}_{k}}{t k_{f}}\left(T_{i, j}-\mathrm{T}_{\infty}\right)
\end{aligned}
$$

where $\bar{h}_{k}$ is the constant heat transfer coefficient on the $k$ th sub-fin region for $k=1,2, \ldots, N$ and will be estimated. $N$ is taken as $6[1,2] \cdot \ell_{r}$ and $\ell_{\theta}$ are $\left(D-d_{0}\right) /$ $\left[2\left(N_{r}-1\right)\right]$ and $2 \pi /\left(N_{\theta}-1\right)$, respectively. The difference

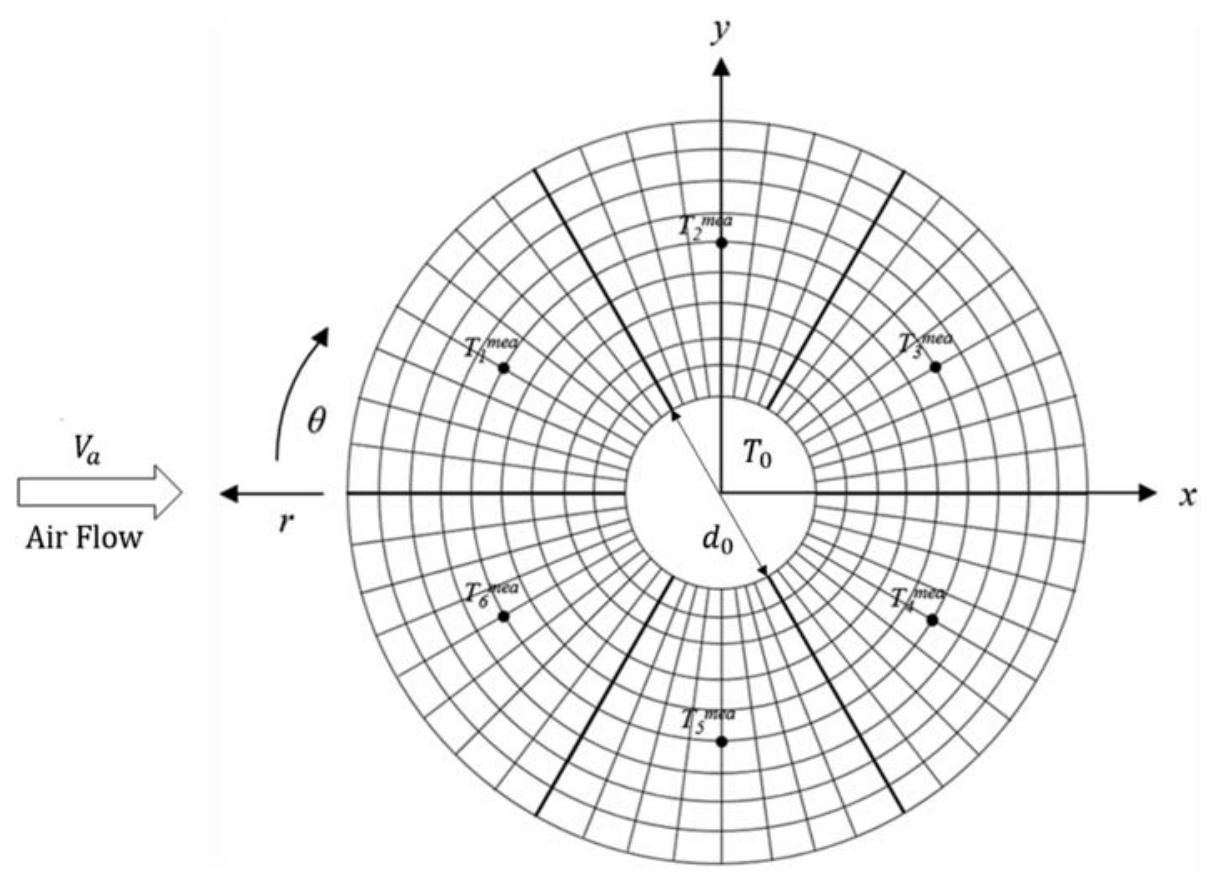

Fig. 1. Physical geometry of IHCM with sub-fin regions and measurement locations. 
equations for the boundary conditions (2)-(4) can be found in Refs. [1,2].

Eq. (6) combined with the difference equations at the interface between two adjacent sub-fins and the boundary can be written as follows.

$[K][T]=[F]$

where $[K]$ is the global conduction matrix. $[T]$ is a matrix representing the node temperature. [F] is the forced matrix. $T_{k}^{m}$ is measured using six $T$-type thermocouples placed at $33.5 \mathrm{~mm}$ from the center of the tube. The uncertainty of these thermocouples is less than $0.4 \%$. $T_{k}^{c}$ is the $T_{k}$ value determined by Eq. (7) using Gaussian elimination. $\bar{h}_{k}$ is estimated by a least-squares minimization technique that minimizes the sum of squares of the deviations between $T_{k}^{c}$ and $T_{k}^{m}$. The estimating $\bar{h}_{k}$ value is repeated until the values of $\left|\left(T_{k}^{m}-T_{k}^{c}\right) / T_{k}^{m}\right|$ are all less than $10^{-5}$. The detailed inverse process can be found in Refs. $[1,4,9]$. The values of $\bar{h}$ and $\bar{h}_{b}$ can be determined from the obtained $\bar{h}_{b}$ value.

\section{3D CFD}

The RNG and STD $k-\epsilon$ models are suitable for low and high Reynolds numbers, respectively, as shown in Ref. [7]. However, the appropriate Reynolds number ranges for these two $k-\epsilon$ models are not explicitly stated. Therefore, how to obtain their Reynolds number range awaits further investigation. It is seen in Refs. [1,2] that more accurate CFD results of this problem can be determined using the zeroequation model for natural convection and the RNG $k-\epsilon$ model with SWF for mixed convection with $V_{a}$ of $1-3 \mathrm{~m} / \mathrm{s}$. The CFD results of STD $k-\epsilon$ model are not presented in Ref. [1] with $V_{a}$ of $1-3 \mathrm{~m} / \mathrm{s}$. Therefore, this study applies RNG, STD and REAL $k-\epsilon$ models in conjunction with SWF and enhanced wall treatment (EWT) to investigate the relationship between $V_{a}$ and the appropriate flow model, especially for $V_{a}$ of $4-5 \mathrm{~m} / \mathrm{s}$. The boundary conditions of the fins in the $r$ and $\theta$ directions are the same as Eqs. (2)-(5). The 3D steady-state FHCE and the remaining boundary conditions are written as follows.

$\nabla^{2} \mathrm{~T}=0$

$\frac{\partial T}{\partial z}=0 \quad$ at $z=0$

and $\frac{\partial T}{\partial z}=-\frac{h(r, \theta)}{k_{f}}\left(T-T_{\infty}\right) \quad$ at $\mathbf{z}=\mathbf{t} / 2$

The flow model is the same throughout the computational domain of this study. As described in Ref. [1,7], the continuity, momentum and energy equations of the three $k-\epsilon$ models with buoyancy effects are written as follows.

$$
\begin{aligned}
\frac{\partial u_{i}}{\partial x_{i}}=0 & \\
u_{j} \frac{\partial u_{i}}{\partial x_{j}}= & -\frac{1}{\rho} \frac{\partial p}{\partial x_{i}}+\nu \frac{\partial}{\partial x_{j}}\left(\frac{\partial u_{j}}{\partial x_{i}}+\frac{\partial u_{i}}{\partial x_{j}}\right)+g_{j} \beta \delta_{j 2}\left(T_{a}-T_{\infty}\right) \\
& -\frac{\partial \overline{u_{i}^{\prime} u_{j}^{\prime}}}{\partial x_{j}}
\end{aligned}
$$

and

$c_{p} u_{j} \frac{\partial T_{a}}{\partial x_{j}}=\frac{k_{e f f}}{\rho} \frac{\partial^{2} T_{a}}{\partial x_{j}^{2}}-c_{p} \frac{\partial \overline{u_{j}^{\prime} T_{a}^{\prime}}}{\partial x_{j}}+2 \nu_{e f f} \frac{\partial}{\partial x_{j}}\left(u_{i} S_{i j}\right)$

where $x_{1}, x_{2}$ and $x_{3}$ denote the Cartesian coordinates $x, y$ and $z . u_{i}, g_{j}, p$ and $T_{a}$ are the velocity component, gravitational acceleration component, pressure and air temperature, respectively. $\rho, \nu, \beta$, $c_{p}, k_{\text {eff }}$ and $\nu_{\text {eff }}$ are the density, kinematic viscosity, volumetric thermal expansion coefficient, specific heat, effective thermal conductivity and effective kinematic viscosity of air, respectively. Turbulent heat flux and Reynolds stress tensor are written as

$-\overline{u_{j}^{\prime} T_{a}^{\prime}}=\frac{c_{p} \nu_{t}}{\operatorname{Pr}_{t}} \frac{\partial T_{a}}{\partial x_{j}}$

and

$-\overline{u_{i}^{\prime} u_{j}^{\prime}}=2 \nu_{t} S_{i j}-2 k \delta_{i j} / 3$

where $\nu_{t}$ and $S_{i j}$ are defined as $\nu_{t}=k^{2} C_{\mu} / \epsilon$ and $S_{i j}=$ $\left(\partial u_{i} / \partial x_{j}+\partial u_{j} / \partial x_{i} /\right) / 2 . P r_{t}$ is 0.85 .

\section{1. $k$ and $\epsilon$ equations}

The $k$ and $\epsilon$ equations are written as follows.

\subsection{1. $R N G k-\epsilon$ model}

$u_{i} \frac{\partial k}{\partial x_{i}}=\frac{\partial}{\partial x_{i}}\left(\nu_{e f f} \alpha_{k} \frac{\partial k}{\partial x_{i}}\right)-\epsilon+\frac{G_{k}+G_{b}}{\rho}$ 
and

$$
\begin{aligned}
u_{i} \frac{\partial \epsilon}{\partial x_{i}}= & \frac{\partial}{\partial x_{i}}\left(\nu_{e f f} \alpha_{\epsilon} \frac{\partial \epsilon}{\partial x_{i}}\right)+C_{1 \epsilon} \frac{\epsilon}{\rho k}\left(C_{3 \epsilon} G_{b}+G_{k}\right)-C_{2 \epsilon} \frac{\epsilon^{2}}{k} \\
& -\frac{C_{\mu} \eta^{3}\left(1-\eta / \eta_{0}\right)}{1+\beta \eta^{3}} \frac{\epsilon^{2}}{k}
\end{aligned}
$$

\subsubsection{STD $k-\epsilon$ model}

$u_{j} \frac{\partial k}{\partial x_{j}}=\frac{\partial}{\partial x_{j}}\left[\left(\nu+\frac{\nu_{t}}{\sigma_{k}}\right) \frac{\partial k}{\partial x_{j}}\right)+\frac{G_{k}+G_{b}}{\rho}-\epsilon$

and

$u_{j} \frac{\partial \epsilon}{\partial x_{j}}=\frac{\partial}{\partial x_{j}}\left[\left(\nu+\frac{\nu_{t}}{\sigma_{\epsilon}}\right) \frac{\partial \epsilon}{\partial x_{j}}\right]+C_{1 \epsilon} \frac{\epsilon}{\rho k}\left(G_{k}+C_{3 \epsilon} G_{b}\right)-C_{2 \epsilon} \frac{\epsilon^{2}}{k}$

\subsubsection{REAL $k-\epsilon$ model}

$u_{j} \frac{\partial k}{\partial x_{j}}=\frac{\partial}{\partial x_{j}}\left[\left(\nu+\frac{\nu_{t}}{\sigma_{k}}\right) \frac{\partial k}{\partial x_{j}}\right)+\frac{G_{k}+G_{b}}{\rho}-\epsilon$

and

$$
\begin{aligned}
u_{j} \frac{\partial \epsilon}{\partial x_{j}}= & \frac{\partial}{\partial x_{j}}\left[\left(\nu+\frac{\nu_{t}}{\sigma_{\epsilon}}\right) \frac{\partial \epsilon}{\partial x_{j}}\right]+C_{1} S_{s} \epsilon-C_{2} \frac{\epsilon^{2}}{k+\sqrt{\nu \epsilon}} \\
& +C_{1 \epsilon} \frac{\epsilon}{\rho k} C_{3 \epsilon} G_{b}
\end{aligned}
$$

where the definitions of $G_{b}, G_{k}$ and $\eta$ and the $\alpha_{k}, \alpha_{\epsilon}$ $C_{1 \epsilon}, C_{2 \epsilon}, C_{\mu}, \beta$ and $\eta_{0}$ values of the RNG $k-\epsilon$ model can be found from Refs. [1,2]. The $\alpha_{k}, \alpha_{\epsilon}, C_{1 \epsilon}, C_{2 \epsilon}$ and $C_{\mu}$ values of the STD $k-\epsilon$ model are 1.0, 1.3, 1.44, 1.92 and 0.09 , respectively. The $\sigma_{k}, \sigma_{\epsilon}, C_{1 \epsilon}, C_{1}$ and $C_{2}$ values of the REAL $k-\epsilon$ model are 1.0, 1.2, 1.44, max $[0.43, \eta /(\eta+5)]$ and 1.9 , respectively. $C_{3 \epsilon}$ for all three $k-\epsilon$ models is set to zero.

\subsection{Boundary conditions}

Only half of the wind tunnel in the flow direction is selected. The physical geometry and computational domain of 3D CFD are presented in Fig. 2, where the computational domain is shown in dashed lines. $u_{1}$ and $T_{a}$ at the inlet of the wind tunnel are given as $V_{a}$ and $T_{\infty}$, respectively. At the outlet of the wind tunnel, the gradient of air velocity and temperature are given as zero. The pressure is one atmosphere. The boundary conditions are assumed to be insulated at the edge of the fin and the side walls of the wind tunnel. No-slip boundary conditions are assumed at the surface of the solid. The gradients of all dependent variables on the side walls of the wind tunnel are assumed to be zero. $\partial u_{i} l$ $\partial z, \partial T_{a} / \partial z$ and $\partial p / \partial z$ are assumed to be zero at $z=0$ or the symmetry line of the wind tunnel. The matching conditions of heat flux and temperature at the air-fin interface are expressed as

$$
T_{a}=T \quad \text { and } \quad k_{a} \frac{\partial T_{a}}{\partial z}=k_{f} \frac{\partial T}{\partial z}
$$

It is found in Refs. $[1,3,4]$ that the total heat transfer rate dissipated from the fin $Q$ is determined by the difference in the enthalpy flow rate at the inlet and outlet positions of the investigated domain. It is worth noting that the values of $Q, \bar{h}$ and $\bar{h}_{b}$ in this study are unknown and should be estimated. The dissipation heat transfer rate in the $k$ th sub-fin region $Q_{k}, \bar{h}$ and $\bar{h}_{b}$ can be approximated as [1-4,6].

$Q_{k}=2 \bar{h}_{k} \int_{A_{k}}\left(T-T_{\infty}\right) d A \approx 2 A_{k} \bar{h}_{k}\left(T_{k}^{m}-T_{\infty}\right)$

and

$Q=\sum_{k=1}^{N} Q_{k}=2 \bar{h}_{b}\left(T_{b}-T_{\infty}\right) A_{f}=2 \bar{h}\left(T_{a v e}-T_{\infty}\right) A_{f}$

where $T_{\text {ave }}$ represents the average of the temperature at all fin grid points. $A_{f}$ is $A_{f}=\pi\left(D^{2}-d_{0}^{2}\right) / 4$. The inverse result of $Q$ obtained by Eqs. (23) and (24) is an approximation. The values of $\bar{h}$ and $\bar{h}_{b}$ can be obtained from Eq. (24) [1-4,6].

The $\bar{h}$ and $Q$ expressions for CFD can be written as

$\bar{h}=\frac{\int_{A_{f}}\left(T_{a}-T_{\infty}\right) h(r, \theta) d A}{\int_{A_{f}}\left(T_{a}-T_{\infty}\right) d A}$

and

$Q=2 \int_{A_{f}} h(r, \theta)\left(T_{a}-T_{\infty}\right) d A$

Eq. (25) for uniform fin temperature can be simplified as

$\bar{h}=\frac{\int_{A_{f}} h(r, \theta) d A}{A_{f}}$ 
The $\bar{h}$ value of FLUENT is determined by Eq. (27).

The friction factor $f$ and the fin efficiency $\eta_{f}$ are written as

$\eta_{f}=\frac{Q}{2 A_{f}\left(T_{b}-T_{\infty}\right) \bar{h}}=\frac{\bar{h}_{b}}{\bar{h}}$

and

$f=\frac{\Delta p}{\rho \mathrm{V}_{a}^{2} / 2} \frac{D}{L_{c}}$

where $\eta_{f}$ can be obtained from Eqs. (24), (27) and (28). $\Delta p$ and $L_{c}$ denote the pressure drop and the length of the computational domain, respectively. $\Delta p$ is defined as $\Delta p=P_{\text {in }}-P_{\text {out }} . P_{\text {in }}$ represents the inlet pressure. The pressure $P_{\text {out }}$ is one atmosphere.
The Richardson number $R i$ and the Rayleigh number $R a$ are defined as $R i=\operatorname{Pr} R a / \operatorname{Re}_{d}^{2}$ and $R a=$ $\frac{g \beta\left(T_{b}-T_{\infty}\right) S^{3}}{\nu \alpha}\left(\frac{S}{D}\right) . \operatorname{Pr}$ is 0.7 . The $R i$ value for $S=15 \mathrm{~mm}$ is $2.24 \times 10^{-5}$ at $V_{a}=4 \mathrm{~m} / \mathrm{s}$ and $1.37 \times 10^{-5}$ at $V_{a}=5 \mathrm{~m} / \mathrm{s}$. Therefore, the effect of natural convection may be negligible.

Chen et al. [1] presented a correlation between $R e_{d}$ and $N u_{d}$ with $V_{a}$ of $1-3 \mathrm{~m} / \mathrm{s}$ for this study. Based on the correlation of Chen et al. [1], this study proposed a new correlation between $R e_{d}$ and $N u_{d}$ with $V_{a}$ of $4-5 \mathrm{~m} / \mathrm{s}$ as follows.

$$
N u_{d}=N u_{n}+N u_{f}=\frac{\bar{h} d_{0}}{k_{a}}
$$

and

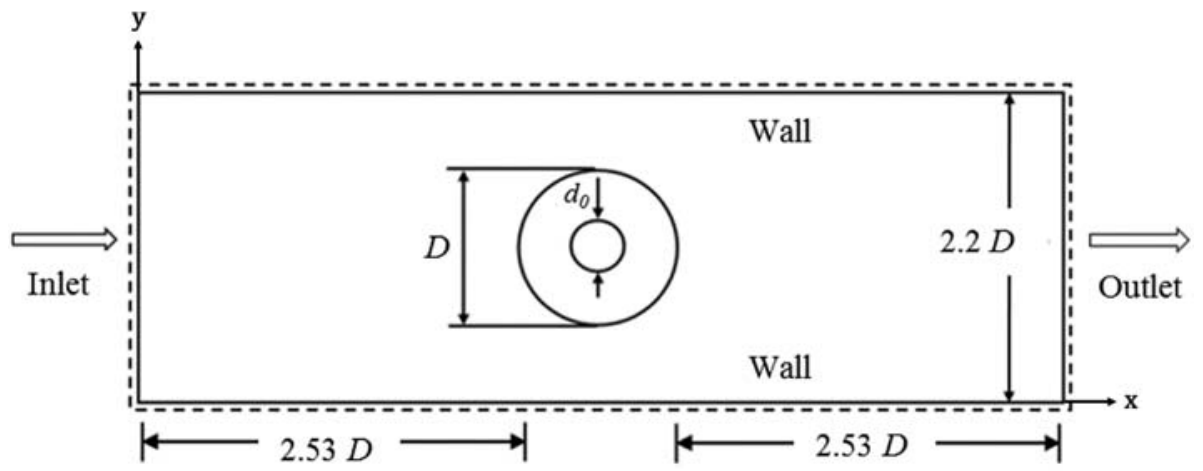

(a)

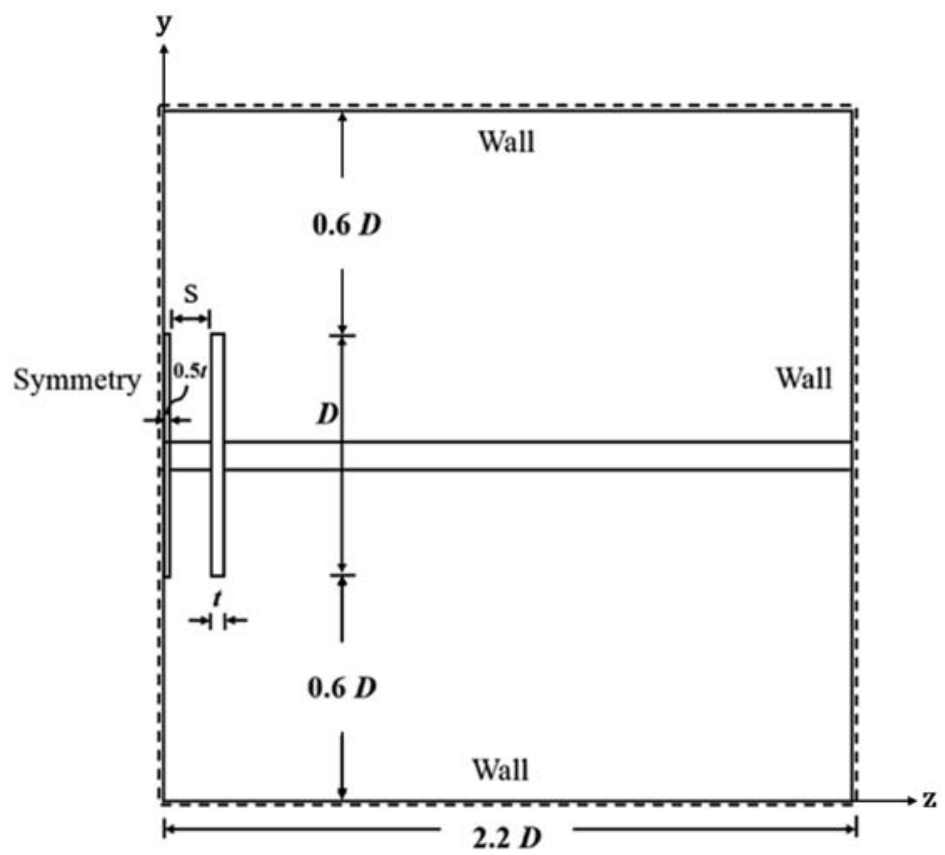

(b)

Fig. 2. Physical geometry and computational domain of $3 D$ CFD with dashed lines. (a) $x-y$ plane, (b) $y-z$ plane. 
$R e_{d}=\frac{V_{a} d_{0}}{\nu}$

It is seen in Eqs. (30) and (31) that $N u_{d}$ contains natural convection and forced convection terms. $N u_{n}$ and $N u_{f}$ are regarded as Nusselt numbers of natural convection and forced convection, respectively. They are defined as

$N u_{n}=\left(-1.85+1.874 R a^{0.255}\right)\left(1-1.65 \frac{d_{0}}{\mathrm{D}}\right) \frac{d_{0}}{S}$

and

$\left.N u_{f}=0.4942\left[\left(\frac{t}{10 S}+1.08\right)\left(1-\frac{K^{*}}{\left(u^{\prime}\right)^{b}\left(R e_{d}\right)^{0.07}}\right) R e_{d}\right]^{0.55}\right\}$

where the definition of $u^{\prime}$ and the values of $b$ and $K^{*}$ can be found in Refs. [11,20].

\section{Typical grid distribution}

$N_{r}$ and $N_{\theta}$ of IHCM are $N_{r}=10$ and $N_{\theta}=48$. The CFD result is obtained by applying grid points with non-uniform distribution. Grid density is controlled to ensure more accurate results. A finer grid is used near the fins and tube. A coarser grid is applied in certain regions with small velocity and temperature gradients. The grid system can be found in Fig. 6 of Ref. [1]. Various grid points were tested until the obtained $T_{k}^{n}$ and $\bar{h}$ values is consistent with $T_{k}^{m}$, the inverse results and correlation (30), respectively. The values of $N_{r}$ and $N_{\theta}$ for the air field between two adjacent fins are the same as those on the fins.

\section{Results and discussion}

To compare the results obtained with those in Ref. [1], $D, d_{o}$ and $t$ are taken as $99 \mathrm{~mm}, 27 \mathrm{~mm}$ and $1 \mathrm{~mm}$, respectively. All thermo-physical properties are obtained at $T_{a}=\left(T_{b}+T_{\infty}\right) / 2$. $T_{k}^{m}$ can be obtained from Ref. [9]. The 2D FHCE combined with the assumption of constant $\bar{h}_{k}$ value $(\mathrm{k}=1,2, . ., 6)$ are applied to estimate $\bar{h}$ and $Q$ values. Therefore, it can be expected that there is a deviation between the $3 \mathrm{D}$ CFD result and the inverse result. Chen et al. [1] did not apply the STD $k-\epsilon$ model to determine numerical results with $V_{a}$ of $1-3 \mathrm{~m} / \mathrm{s}$. Thus, Table 1 presents the numerical results of the STD $k-\epsilon$ model

Table 1. Comparison of CFD results for STD $k-\epsilon$ model with $S=5 \mathrm{~mm}$ T0.

\begin{tabular}{lllll}
\hline & \multicolumn{2}{l}{$N_{t}=89,349, V_{a}=1 \mathrm{~m} / \mathrm{s}$} & & $N_{t}=87,085, V_{a}=3 \mathrm{~m} / \mathrm{s}$, \\
\cline { 2 - 3 } & EWT & SWF & EWT & 302.43 \\
\hline$T_{1}(\mathrm{~K})$ & 303.54 & 304.97 & 305.22 & 302.18 \\
$T_{2}(\mathrm{~K})$ & 307.41 & 307.86 & 310.33 & 311.12 \\
$T_{3}(\mathrm{~K})$ & 312.83 & 314.65 & 309.45 & 311.01 \\
$T_{4}(\mathrm{~K})$ & 311.91 & 314.44 & 303.87 & 304.10 \\
$T_{5}(\mathrm{~K})$ & 305.15 & 307.76 & 302.15 & 302.18 \\
$T_{6}(\mathrm{~K})$ & 302.76 & 304.96 & 43.20 & 42.98 \\
$\bar{h}\left(\mathrm{~W} / \mathrm{m}^{2} \mathrm{~K}\right)$ & 31.52 & 22.83 & 8.49 & 3.26 \\
$\bar{h}\left(\mathrm{~W} / \mathrm{m}^{2} \mathrm{~K}\right)$ & 7.29 & 6.04 & 4.05 & 3.94 \\
$Q(\mathrm{~W})$ & 3.38 & 2.80 & 4.39 & 3.03 \\
$y^{+}$ & 2.97 & 1.84 & & \\
\hline
\end{tabular}

Table 2. Comparison of results for $V_{a}=4 \mathrm{~m} / \mathrm{s}, \mathrm{S}=5 \mathrm{~mm}, \mathrm{~T}_{\infty}=298.70 \mathrm{~K}, \mathrm{~T}_{b}=330.80 \mathrm{~K}$ and $\mathrm{N}_{t}=465,292 \mathrm{~T} 0$.

\begin{tabular}{|c|c|c|c|c|c|c|}
\hline & \multirow[t]{2}{*}{ Exp. data } & \multirow[t]{2}{*}{ STD k- $\epsilon$ SWF } & \multicolumn{2}{|c|}{ RNG k- $\epsilon$} & \multicolumn{2}{|c|}{ REAL k- $\epsilon$} \\
\hline & & & EWT & SWF & EWT & SWF \\
\hline$T_{1}(\mathrm{~K})$ & 301.37 & 302.51 & 304.85 & 303.63 & 300.39 & 299.16 \\
\hline$T_{2}(\mathrm{~K})$ & 301.96 & 304.51 & 306.91 & 305.16 & 301.24 & 299.17 \\
\hline$T_{3}(\mathrm{~K})$ & 308.04 & 310.44 & 311.64 & 310.95 & 304.57 & 299.90 \\
\hline$T_{4}(\mathrm{~K})$ & 310.98 & 310.41 & 311.58 & 310.83 & 304.19 & 300.62 \\
\hline$T_{5}(\mathrm{~K})$ & 301.76 & 304.41 & 306.95 & 305.00 & 301.19 & 299.35 \\
\hline$T_{6}(\mathrm{~K})$ & 300.39 & 302.51 & 304.95 & 303.71 & 300.44 & 299.26 \\
\hline $\bar{h}\left(\mathrm{~W} / \mathrm{m}^{2} \mathrm{~K}\right)$ & 41.53 (Inv.) & 43.20 & 22.30 & 36.10 & 92.57 & 114.82 \\
\hline $\bar{h}_{b}\left(\mathrm{~W} / \mathrm{m}^{2} \mathrm{~K}\right)$ & 6.18 (Inv.) & 7.62 & 5.87 & 7.07 & 12.16 & 22.10 \\
\hline$Q(\mathrm{~W})$ & 2.83 (Inv.) & 3.48 & 2.68 & 3.24 & 5.55 & 8.71 \\
\hline$y^{+}$ & - & 1.46 & 0.91 & 1.24 & 6.39 & 15.53 \\
\hline
\end{tabular}


Table 3. Comparison of results for $V_{a}=5 \mathrm{~m} / \mathrm{s}, S=5 \mathrm{~mm}, T_{\infty}=298.90 \mathrm{~K}, \mathrm{~T}_{b}=330.13 \mathrm{~K}$ and $\mathrm{N}_{t}=465,292 . \mathrm{T0}$.

\begin{tabular}{|c|c|c|c|c|c|c|}
\hline & \multirow[t]{2}{*}{ Exp. data } & \multirow[t]{2}{*}{ STD $k-\epsilon$ SWF } & \multicolumn{2}{|c|}{ RNG $k-\epsilon$} & \multicolumn{2}{|c|}{ REAL $k-\epsilon$} \\
\hline & & & EWT & SWF & EWT & SWF \\
\hline$T_{1}(\mathrm{~K})$ & 300.98 & 302.15 & 305.50 & 302.91 & 299.82 & 299.28 \\
\hline$T_{2}(\mathrm{~K})$ & 301.37 & 303.79 & 307.75 & 304.87 & 300.17 & 299.31 \\
\hline$T_{3}(\mathrm{~K})$ & 306.43 & 309.66 & 313.74 & 312.36 & 302.92 & 300.10 \\
\hline$T_{4}(\mathrm{~K})$ & 308.75 & 309.55 & 313.18 & 312.48 & 303.28 & 300.22 \\
\hline$T_{5}(\mathrm{~K})$ & 300.98 & 303.84 & 307.27 & 304.95 & 300.28 & 299.25 \\
\hline$T_{6}(\mathrm{~K})$ & 300.86 & 302.24 & 305.42 & 302.94 & 299.87 & 299.25 \\
\hline $\bar{h}\left(\mathrm{~W} / \mathrm{m}^{2} \mathrm{~K}\right)$ & 45.29 (Inv.) & 49.30 & 23.5 & 40.51 & 123.35 & 165.42 \\
\hline $\bar{h}_{b}\left(\mathrm{~W} / \mathrm{m}^{2} \mathrm{~K}\right)$ & 6.28 (Inv.) & 8.06 & 6.12 & 7.47 & 15.08 & 27.28 \\
\hline$Q(W)$ & 2.79 (Inv.) & 3.58 & 2.72 & 3.32 & 6.70 & 12.12 \\
\hline$y^{+}$ & - & 1.63 & 0.96 & 1.46 & 10.02 & 61.78 \\
\hline
\end{tabular}

Table 4. Comparison of results for $V_{a}=4 \mathrm{~m} / \mathrm{s}, S=15 \mathrm{~mm}, T_{\infty}=299.82 \mathrm{~K}, \mathrm{~T}_{b}=331.00 \mathrm{~K}$ and $\mathrm{N}_{t}=465,292 \mathrm{~T}$.

\begin{tabular}{|c|c|c|c|c|c|c|}
\hline & \multirow[t]{2}{*}{ Exp. data } & \multirow[t]{2}{*}{ STD $k-\epsilon$ SWF } & \multicolumn{2}{|c|}{ RNG $k-\epsilon$} & \multicolumn{2}{|c|}{ REAL $k-\epsilon$} \\
\hline & & & EWT & SWF & EWT & SWF \\
\hline$T_{1}(\mathrm{~K})$ & 301.84 & 302.56 & 306.10 & 302.12 & 301.47 & 300.62 \\
\hline$T_{2}(\mathrm{~K})$ & 302.39 & 303.94 & 307.66 & 303.31 & 302.43 & 300.48 \\
\hline$T_{3}(\mathrm{~K})$ & 305.41 & 308.06 & 311.06 & 307.39 & 305.51 & 301.95 \\
\hline$T_{4}(\mathrm{~K})$ & 306.72 & 307.96 & 311.26 & 307.42 & 305.54 & 301.02 \\
\hline$T_{5}(\mathrm{~K})$ & 302.43 & 303.97 & 307.83 & 303.45 & 302.43 & 300.52 \\
\hline$T_{6}(\mathrm{~K})$ & 301.80 & 302.63 & 306.27 & 302.22 & 301.51 & 300.50 \\
\hline $\bar{h}\left(\mathrm{~W} / \mathrm{m}^{2} \mathrm{~K}\right)$ & 58.10 (Inv.) & 59.70 & 25.30 & 49.60 & 93.33 & 115.76 \\
\hline $\bar{h}_{b}\left(\mathrm{~W} / \mathrm{m}^{2} \mathrm{~K}\right)$ & 6.73 (Inv.) & 8.70 & 6.80 & 8.75 & 11.86 & 21.10 \\
\hline$Q(W)$ & 2.99 (Inv.) & 3.86 & 3.01 & 3.88 & 5.26 & 9.36 \\
\hline$y^{+}$ & - & 1.39 & 0.82 & 1.21 & 6.21 & 18.8 \\
\hline
\end{tabular}

with SWF and EWT for $S=5 \mathrm{~mm}$ and $V_{a}=1 \mathrm{~m} / \mathrm{s}$ and $3 \mathrm{~m} / \mathrm{s}$. Tables $2-5$ show a comparison between the CFD results obtained from three different $k-\epsilon$ models in combination with SWF and EWT, inverse results and $T_{k}^{m}$ for $V_{a}=4 \mathrm{~m} / \mathrm{s}$ and $5 \mathrm{~m} / \mathrm{s}$. It is observed from Tables 2 and 4 of Ref. [1] and Tables 1-5 that the $T_{k}^{n}$ value of the STD $k-\epsilon$ model with EWT is slightly closer to $T_{k}^{m}$ than that with SWF. However, $\bar{h}_{,} \bar{h}_{b}$ and $Q$ of the STD $k-\epsilon$ model with SWF are closer to their inverse results than those with EWT. Thus, it is important to select the appropriate flow model and wall function. This result implies that although the $T_{k}^{n}$ value obtained is close to $T_{k}^{m}$, the CFD results of $\bar{h}$ and $Q$ may deviate from the inverse results. In addition, the difference in $T_{k}^{n}$ obtained from the STD and RNG $k-\epsilon$ models in conjunction with SWF is small for $V_{a}$ of $1-3 \mathrm{~m} / \mathrm{s}$. But, $\bar{h}$ and $Q$ obtained from these two $k-\epsilon$ models may be slightly different. Therefore, the RNG $k-\epsilon$ model and SWF are more appropriate for this problem than the STD $k-\epsilon$ model with $V_{a}$ of $1-3 \mathrm{~m} / \mathrm{s}$, as shown in Ref. [1]. It is found in Tables $2-5$ that the difference in $T_{k}^{n}$ obtained from the STD and RNG $k-\epsilon$ models in combination with SWF is small

Table 5. Comparison of results for $V_{a}=5 \mathrm{~m} / \mathrm{s}, S=15 \mathrm{~mm}, T_{\infty}=299.53 \mathrm{~K}, \mathrm{~T}_{b}=329.30 \mathrm{~K}$ and $\mathrm{N}_{t}=465,292 \mathrm{T0}$.

\begin{tabular}{|c|c|c|c|c|c|c|}
\hline & \multirow[t]{2}{*}{ Exp. data } & \multirow[t]{2}{*}{ STD $k-\epsilon$ SWF } & \multicolumn{2}{|c|}{ RNG $k-\epsilon$} & \multicolumn{2}{|c|}{ REAL $k-\epsilon$} \\
\hline & & & EWT & SWF & $\overline{\text { EWT }}$ & $\overline{S W F}$ \\
\hline$T_{1}(\mathrm{~K})$ & 301.18 & 301.85 & 305.21 & 302.37 & 300.04 & 299.88 \\
\hline$T_{2}(\mathrm{~K})$ & 301.64 & 303.11 & 305.55 & 303.26 & 301.07 & 299.83 \\
\hline$T_{3}(\mathrm{~K})$ & 304.43 & 306.80 & 308.46 & 306.92 & 304.32 & 300.57 \\
\hline$T_{4}(\mathrm{~K})$ & 305.25 & 306.72 & 308.47 & 307.20 & 304.19 & 300.51 \\
\hline$T_{5}(\mathrm{~K})$ & 301.48 & 303.04 & 305.58 & 303.37 & 301.06 & 299.91 \\
\hline$T_{6}(\mathrm{~K})$ & 301.18 & 301.98 & 305.30 & 302.56 & 300.08 & 299.93 \\
\hline$h \mathrm{~W} /\left(\mathrm{m}^{2} \mathrm{~K}\right)$ & 65.97 (Inv.) & 65.80 & 31.50 & 57.60 & 102.06 & 137.21 \\
\hline $\bar{h}_{b} \mathrm{~W} /\left(\mathrm{m}^{2} \mathrm{~K}\right)$ & 6.64 (Inv.) & 9.26 & 6.85 & 8.93 & 12.61 & 22.15 \\
\hline$Q(W)$ & 2.82 (Inv.) & 3.92 & 2.90 & 3.78 & 5.34 & 9.38 \\
\hline$y^{+}$ & - & 1.56 & 1.28 & 1.56 & 7.3 & 33.6 \\
\hline
\end{tabular}


Table 6. Effect of $N_{t}$ on the results of STD $k-\epsilon$ model with $V_{a}=5 \mathrm{~m} / \mathrm{s}$.

\begin{tabular}{|c|c|c|c|c|c|c|c|}
\hline & \multicolumn{7}{|c|}{$N_{z f} \times N_{z a}$} \\
\hline & \multicolumn{3}{|c|}{$\mathrm{S}=5 \mathrm{~mm}$} & \multicolumn{4}{|c|}{ Single fin $(S \rightarrow \infty)$} \\
\hline & $5 \times 11$ & $9 \times 12$ & $7 \times 9$ & $5 \times 32$ & $5 \times 148$ & $9 \times 158$ & Exp. data \\
\hline$T_{1}(\mathrm{~K})$ & 301.58 & 302.15 & 302.58 & 302.20 & 301.75 & 301.54 & 301.44 \\
\hline$T_{2}(\mathrm{~K})$ & 302.83 & 303.79 & 303.85 & 302.95 & 302.38 & 302.30 & 302.39 \\
\hline$T_{3}(\mathrm{~K})$ & 308.50 & 309.66 & 308.82 & 305.57 & 304.90 & 305.12 & 304.13 \\
\hline$T_{4}(\mathrm{~K})$ & 308.32 & 309.55 & 308.78 & 305.57 & 304.90 & 305.07 & 304.92 \\
\hline$T_{5}(\mathrm{~K})$ & 302.79 & 303.84 & 303.84 & 302.95 & 302.38 & 302.29 & 302.13 \\
\hline$T_{6}(\mathrm{~K})$ & 301.56 & 302.24 & 302.58 & 302.20 & 301.76 & 301.53 & 301.61 \\
\hline $\bar{h}\left(\mathrm{~W} / \mathrm{m}^{2} \mathrm{~K}\right)$ & 62.32 & 49.30 & 58.1 & 77.6 & 74.91 & 88.70 & 773.95 \\
\hline $\bar{h}_{b}\left(\mathrm{~W} / \mathrm{m}^{2} \mathrm{~K}\right)$ & 8.82 & 8.06 & 7.56 & 9.33 & 9.27 & 10.99 & 6.76 \\
\hline$Q(\mathrm{~W})$ & 3.92 & 3.58 & 3.36 & 4.20 & 4.06 & 4.96 & 3.05 \\
\hline$N_{t}$ & 452,222 & 465,292 & 458,490 & 146,384 & 311,066 & 428,696 & \\
\hline
\end{tabular}

for $V_{a}$ of $4-5 \mathrm{~m} / \mathrm{s}$. However, the $\bar{h}$ value of the STD $k-\epsilon$ model with SWF is closer to the inverse result than that of the RNG and REAL $k-\epsilon$ models. In accordance with the above results, the STD $k-\epsilon$ model with SWF are more suitable for this problem with $V_{a}$ of $4-5 \mathrm{~m} / \mathrm{s}$ compared to RNG and REAL $k-\epsilon$ models. The REAL $k-\epsilon$ model may be more suitable for problems with faster speeds compared to the zero-equation and RNG and STD $k-\epsilon$ models. These results are different from Table 2 in Ref. [13]. In addition, the $\bar{h}$ value of the REAL $k-\epsilon$ model with SWF is greater than that with EWT for $R e_{d}$ of 6150-7800. It is found from Fig. 7 in Ref. [8] that the Nusselt number of the REAL $k-\epsilon$ model and NEWF agrees with experimental data for $R e$ of $400-800$ and deviates from the experimental data for $R e$ of 1000-1400. The Nusselt number of the REAL $k-\epsilon$ model with EWT is greater than that with SWF for $R e$ of 400-1400. This difference may be attributed to the independence between the selection of $k-\epsilon$ model and $V_{a}$. Therefore, both the inverse result of $\bar{h}$ and $T_{k}^{m}$ need to be compared. The appropriate $R e_{d}$ ranges for the RNG and STD $k-\epsilon$ models of this study fall between 570 and 4600 and between 6150 and 7,850 , respectively.

It is seen from Tables $1-5$ and Tables 2 and 4 of Ref. [1] that $\bar{h}$ and $Q$ of the RNG and REAL $k-\epsilon$ models with SWF are larger than those with EWT for $V_{a}$ of $1-5 \mathrm{~m} / \mathrm{s}$. The $\bar{h}$ value of the STD $k-\epsilon$ model with SWF is lower than that with EWT for $V_{a}$ of $1 \mathrm{~m} /$ $\mathrm{s}$ and $3 \mathrm{~m} / \mathrm{s}$. The $\bar{h}$ value of the STD $k$ - $\epsilon$ model with SWF is 0.72 time and 1.01 times that of EWT, respectively, for $S=5 \mathrm{~mm}$ and $V_{a}=1 \mathrm{~m} / \mathrm{s}$ and $3 \mathrm{~m} / \mathrm{s}$. The $\bar{h}$ value of the RNG $k-\epsilon$ model with SWF is 1.11 times, 1.97 times, 1.62 times and 1.72 times that of EWT, respectively, for $S=5 \mathrm{~mm}$ and $V_{a}=1 \mathrm{~m} / \mathrm{s}$, $3 \mathrm{~m} / \mathrm{s}, 4 \mathrm{~m} / \mathrm{s}$ and $5 \mathrm{~m} / \mathrm{s}$. The $\bar{h}$ value of the STD $k-\epsilon$ model can be 1.14 times that of the RNG $k-\epsilon$ model and 0.48 times that of the REAL $k-\epsilon$ model with SWF, $V_{a}=5 \mathrm{~m} / \mathrm{s}$ and $S=15 \mathrm{~mm}$. The $\bar{h}$ value of the REAL $k-\epsilon$ model with SWF is 1.56 times and 1.34 times that of EWT, respectively, for $S=5 \mathrm{~mm} V_{a}=4 \mathrm{~m} / \mathrm{s}$ and $5 \mathrm{~m} / \mathrm{s}$. This result is different from that in Fig. 7 of Ref. [8] for $R e$ of $400-1400$. It is known that the $Q$ value is not easy to estimate. It can be predicted from the obtained $\bar{h}$ estimate. The $Q$ value of the STD $k-\epsilon$ model can be 1.04 times that of the RNG $k-\epsilon$ model and 0.42 times that of the REAL $k-\epsilon$ model with $S W F, V_{a}=5 \mathrm{~m} / \mathrm{s}$ and $S=15 \mathrm{~mm}$. This means that if the estimation of $\bar{h}$ is not accurate enough, it may affect the estimation of the $Q$ value. Therefore, it is important to select the appropriate flow model and wall function. As far as we know, these findings have not yet been proposed. This study has

Table 7. Comparison of $h$ and $h_{b}$ between CFD and inverse results with $V_{a}$ of $4 \mathrm{~m} / \mathrm{s}$ and $5 \mathrm{~m} / \mathrm{s}$.

\begin{tabular}{|c|c|c|c|c|c|c|c|c|c|}
\hline \multirow[t]{2}{*}{$\overline{S(\mathrm{~mm})}$} & \multirow[t]{2}{*}{$V_{a}(\mathrm{~m} / \mathrm{s})$} & \multirow[t]{2}{*}{$R e_{d}$} & \multirow[t]{2}{*}{$\bar{f}$} & \multicolumn{4}{|c|}{$\bar{h}\left(\mathrm{~W} /\left(\mathrm{m}^{2} \mathrm{~K}\right)\right.$} & \multicolumn{2}{|c|}{$\bar{h}_{b}\left(\mathrm{~W} /\left(\mathrm{m}^{2} \mathrm{~K}\right)\right.$} \\
\hline & & & & Inv. & CFD & Eq. (30) & Eq. (33) & Inv. & CFD \\
\hline \multirow[t]{2}{*}{5} & 4 & 6146.13 & 0.12 & 41.53 & 43.20 & 42.30 & 42.11 & 6.18 & 7.62 \\
\hline & & 7780.89 & 0.09 & 45.29 & 49.30 & 50.90 & 48.00 & 6.28 & 8.06 \\
\hline \multirow[t]{2}{*}{10} & 4 & 6179.56 & 0.12 & 54.80 & 55.30 & 55.49 & 46.53 & 6.74 & 8.50 \\
\hline & & 7833.44 & 0.09 & 60,60 & 63.70 & 59.47 & 52.85 & 6.73 & 9.07 \\
\hline \multirow[t]{2}{*}{15} & 4 & 6259.94 & 0.12 & 58.10 & 59.70 & 57.03 & 48.26 & 6.73 & 8.70 \\
\hline & 5 & 7870.95 & 0.09 & 65.97 & 65.80 & 64.26 & 54.76 & 6.63 & 9.26 \\
\hline \multirow[t]{2}{*}{$\infty$} & 4 & 6266.20 & 0.10 & 67.12 & 67.60 & - & - & 6.88 & 10.67 \\
\hline & 5 & 7812.06 & 0.07 & 73.95 & 73.78 & - & - & 6.76 & 10.96 \\
\hline
\end{tabular}


academic innovations and practical applications, such as energy-saving design of factory buildings and glass curtain buildings, high-performance heat exchangers and ventilation design of hospital emergency rooms and operating rooms.

The $y^{+}$values of the STD, RNG and REAL $k-\epsilon$ models combined with SWF for $S=5 \mathrm{~mm}$ are, respectively, 1.24, 1.46 and 15.53 at $V_{a}=4 \mathrm{~m} / \mathrm{s}$ and $1.46,1.63$ and 61.78 at $V_{a}=5 \mathrm{~m} / \mathrm{s}$. The $y^{+}$values of the RNG, STD and REAL $k-\epsilon$ models combined with SWF for $S=15 \mathrm{~mm}$ are, respectively, 1.21, 1.39 and 18.8 at $V_{a}=4 \mathrm{~m} / \mathrm{s}$ and $1.56,1.56$ and 33.6 at $V_{a}=5 \mathrm{~m} /$ s. Table 1 shows that $y^{+}$can increase with $V_{a}$. The similar results can be found in Tables 2 and 4 of Ref. [1]. It is found in Ref. [13] that the value of $y^{+}$nowhere exceeds 7 at $V_{a}=2 \mathrm{~m} / \mathrm{s}$ for the basic grid with 95,760 cells. Then, the $y^{+}$value is adjusted to be less than 3 for each method. Similar results are obtained across all $k-\epsilon$ models. However, the results of the RNG $k-\epsilon$ model are more similar to those of the STD $k-\epsilon$ model compared to the REAL $k-\epsilon$ model. In addition, the $y^{+}$value in Ref. [14] is assumed to be less than 3. It is found in Refs. [10,23] that for all 2D RANS models, the $y^{+}$corresponding to the first grid close to the wall is about 1 for a grid resolution of $60 \times 60$ and about 0.3 for $25 \times 150$ non- uniform grid. The required $y^{+}$value is in the range of 30-300 for $k-\epsilon$ models and SWF. Rincón-Casado et al. [17] pointed out that for the case of the $k-\epsilon$ model with EWT, $y^{+}$must be close to 1 . A more accurate prediction of $y^{+}$for all RANS models and various near-wall treatments is not presented in Refs. $[8,10,14,17,23]$. An interesting finding is that $y^{+}$may generally not be very sensitive to $S$. For $V_{a}$ of $4-5 \mathrm{~m} / \mathrm{s}, y^{+}$of RNG and STD $k-\epsilon$ models with SWF or EWT does not exceed 3 and the difference between them is small. These results are in good agreement with those in Refs. [13,14,23]. However, $y^{+}$of the REAL $k-\epsilon$ model with SWF exceeds 7 and is much larger than that with EWT. This result does not support those in Refs. $[10,13,14,17,23]$. Therefore, the comparison and estimation of $y^{+}$obtained by $k-\epsilon$ models and near-wall treatments are of great significance. To the best of our knowledge, scant evidence exists regarding such comparisons and estimates based on experimental data.

$N_{z f}$ and $N_{z a}$ indicate the number of grid points on the fins and in the air field between a single fin and the side wall of a wind tunnel or between two adjacent fins, respectively. Table 6 presents the effect of grid points on the $T_{k}^{n}, \bar{h}$ and $Q$ values of the STD $k-\epsilon$ model with $N_{r}=14, N_{\theta}=76$ and two
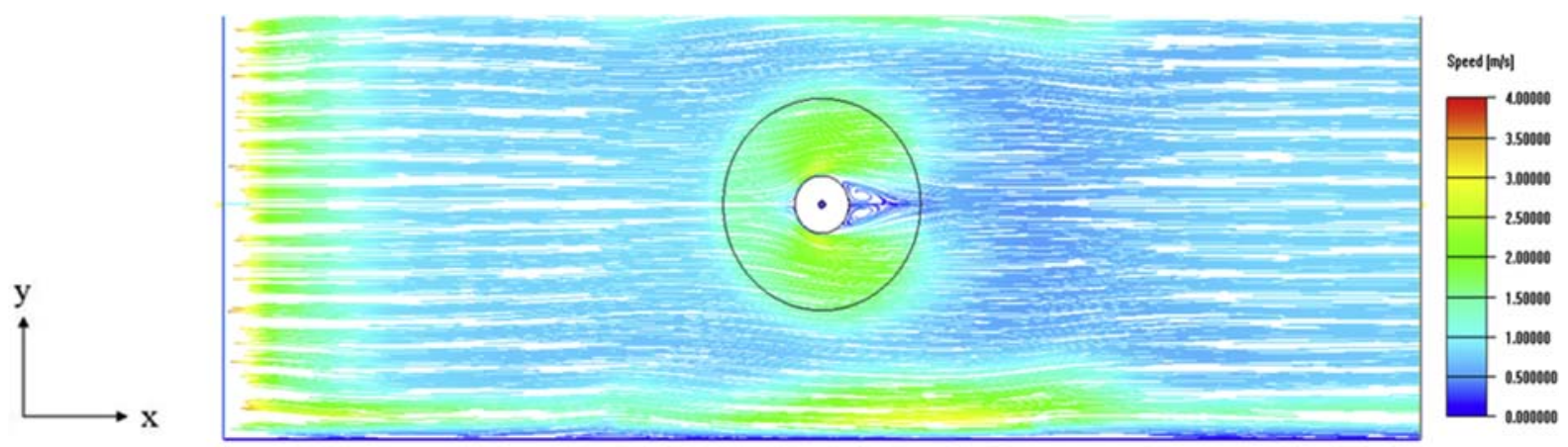

(a)
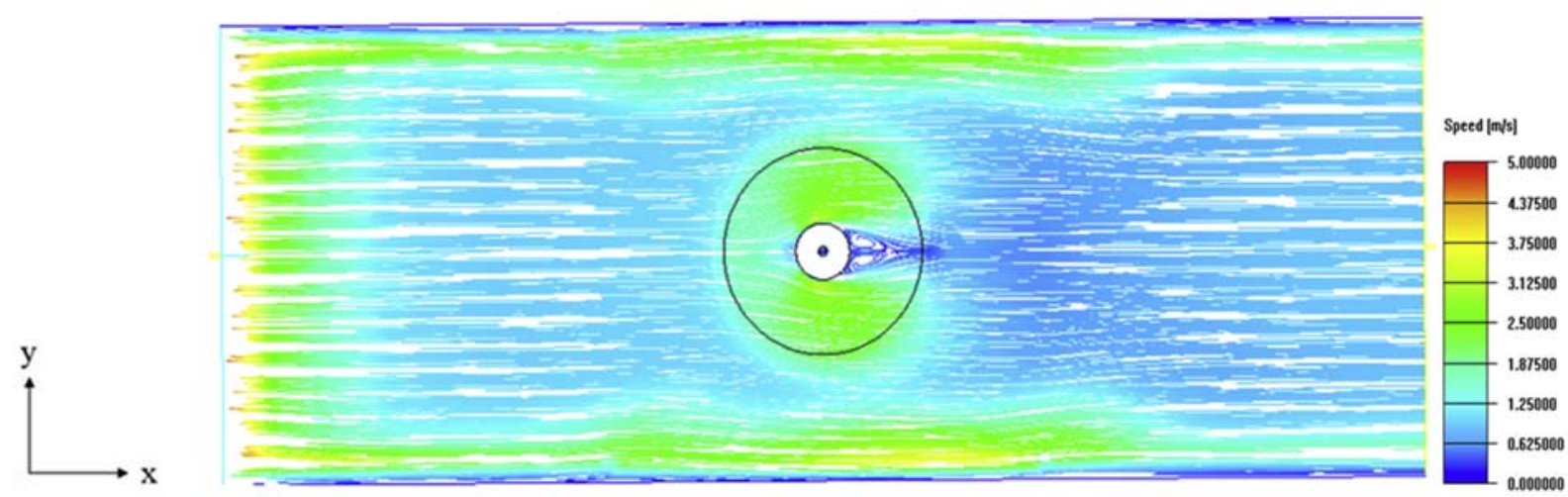

(b)

Fig. 3. Velocity pattern of $S=5 \mathrm{~mm}$ at $z=S / 2$. (a) $V_{a}=4 \mathrm{~m} / \mathrm{s}$, (b) $V_{a}=5 \mathrm{~m} / \mathrm{s}$. 


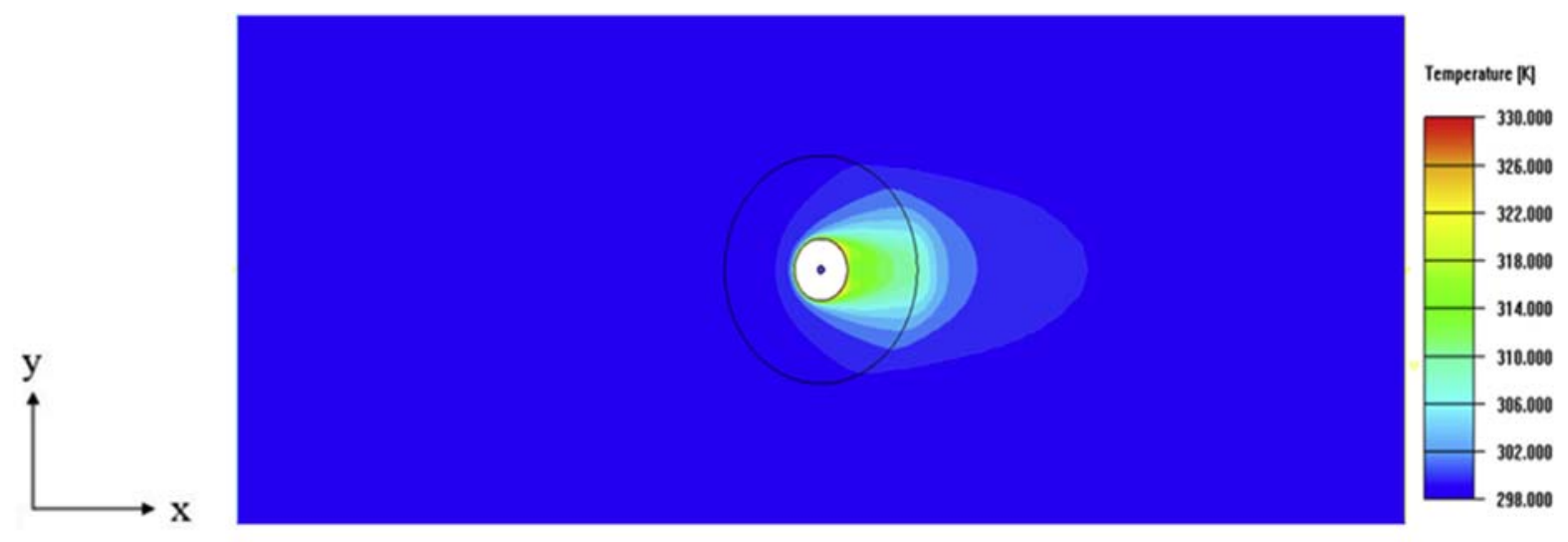

(a)

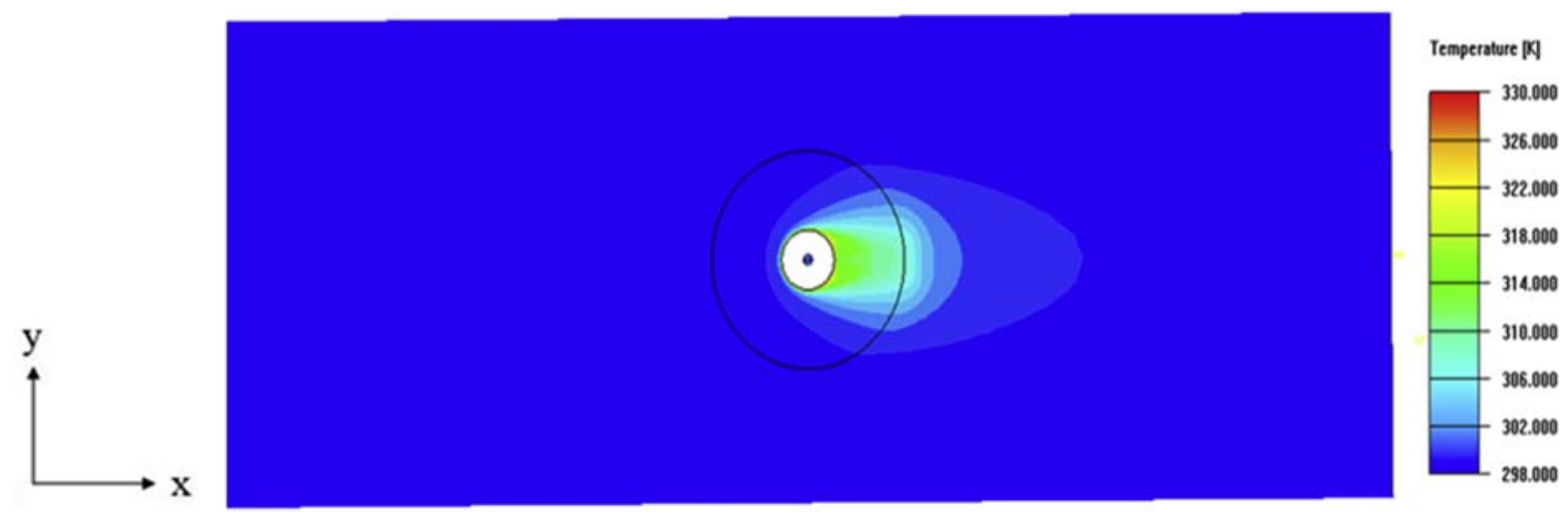

(b)

Fig. 4. Air temperature contours of $S=5 \mathrm{~mm}$ at $z=S / 2$. (a) $V_{a}=4 \mathrm{~m} / \mathrm{s}$, (b) $V_{a}=5 \mathrm{~m} / \mathrm{s}$.

different $S$ values at $V_{a}=5 \mathrm{~m} / \mathrm{s}$. It is found from Tables 3,5 and 6 that $\bar{h}$ and $T_{k}^{n}$ values obtained using $N_{z f}=9$ and $N_{z a}=12$ for $S=5 \mathrm{~mm}$ and $N_{z f}=9$ and $N_{z a}=148$ for a single fin $(S \rightarrow \infty)$ are closer to $T_{k}^{m}$ and the estimation of $\bar{h}$ compared to other grid points. It is observed in Ref. [1] that $N_{z f}$ and $N_{z a}$ may need to increase with increasing $V_{a}$. In other words, the effect of $N_{z f}$ and $N_{z a}$ on the CFD results obtained should not be ignored, as shown in Table 5. This phenomenon may be caused by the fact that the thermal boundary layer on the fin becomes thinner as $V_{a}$ increases. The choice of $N_{z f}$ and $N_{z a}$ may be based on $T_{k}^{m}$ and the estimation of $\bar{h}$. The increase of $N_{t}$ will increase the value of $\bar{h}$ when $S \rightarrow \infty$, but the accuracy of $T_{k}^{n}$ may not be improved. This result indicates that more accurate results are not warranted with increasing $N_{t}$. The $N_{t}$ value at $V_{a}=5 \mathrm{~m} / \mathrm{s}$ is taken as 465,292 for $S=5 \mathrm{~mm}$ and 311,006 when $S$ $\rightarrow \infty$. Therefore, the $N_{t}$ value of $S=5 \mathrm{~mm}$ is greater at $V_{a}=5 \mathrm{~m} / \mathrm{s}$ than at $V_{a}=1 \mathrm{~m} / \mathrm{s}$ and $3 \mathrm{~m} / \mathrm{s}$. This means that $N_{t}$ may vary with $V_{a}$ for a fixed $S$ value. Thus, the assumption of grid independence may not be appropriate for this study.

The comparison of $\bar{h}$ and $\bar{h}_{b}$ between the CFD results obtained by the STD $k-\epsilon$ model with SWF, the inverse results and the proposed correlations (30) and (33) are shown in Table 7 for $V_{a}$ of $4 \mathrm{~m} / \mathrm{s}$ and $5 \mathrm{~m} / \mathrm{s}$. The results indicate that the CFD result of $\bar{h}$ is consistent with the correlation (30) and inverse results for $V_{a}$ of $4 \mathrm{~m} / \mathrm{s}$ and $5 \mathrm{~m} / \mathrm{s}$. Therefore, the proposed correlation (30) has better accuracy for $V_{a}$ of 1-5 m/s than for correlation (33). However, the CFD result of $\bar{h}_{b}$ deviates slightly from its inverse result. For smaller $R i$ values, the natural convection of hot air moving upwards caused by parallel fins is not obvious, and the effect of forced convection is dominant. However, the impact of natural convection may not be ignored. For $S=15 \mathrm{~mm}$, the $\bar{h}$ results obtained from the proposed correlation (30) are slightly different from those obtained from the correlation (33). This difference is due 


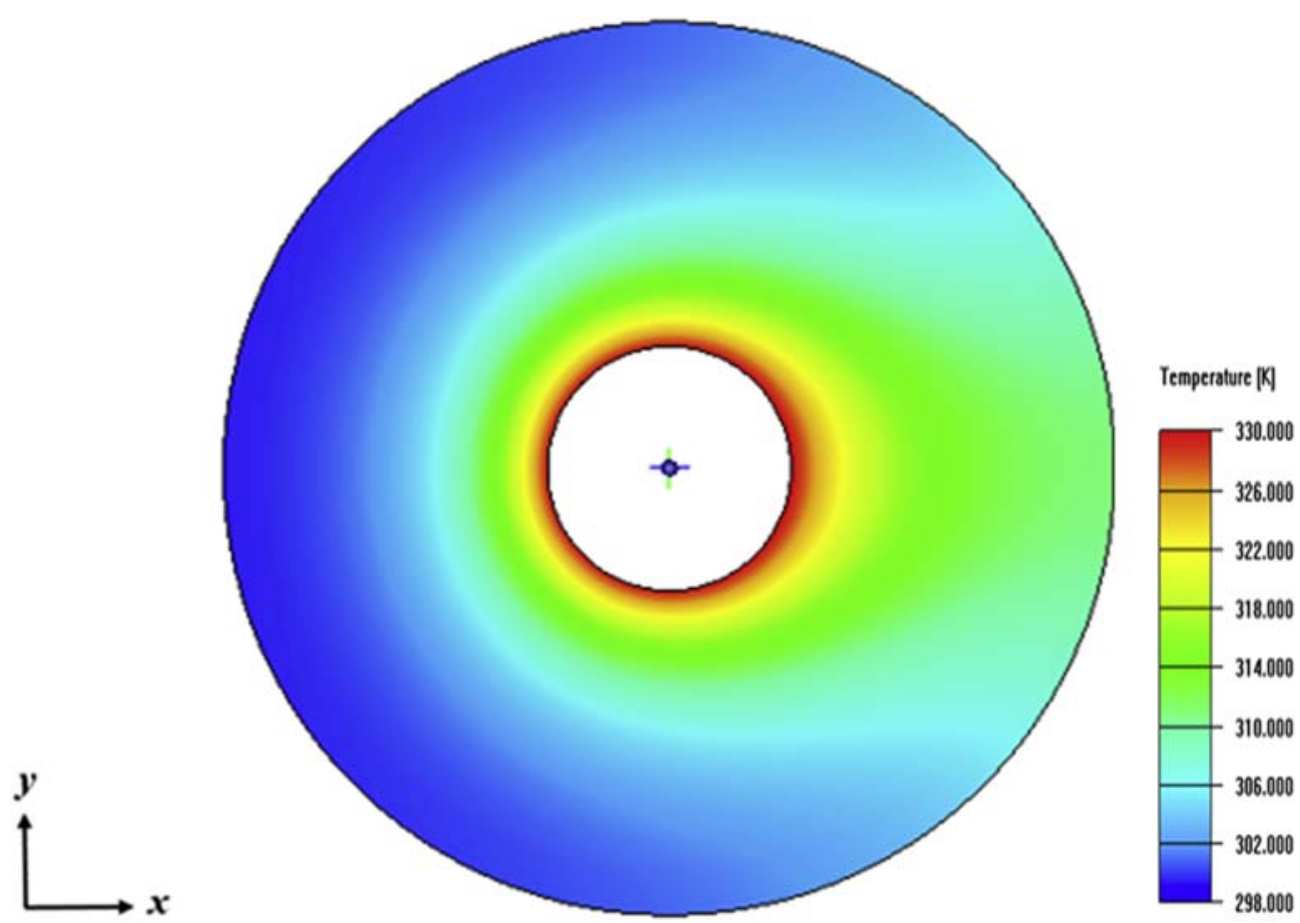

Fig. 5. Surface temperature contours of fins with $V_{a}=4 \mathrm{~m} / \mathrm{s}$.

to the absence of natural convection in correlation (33). The difference in $\bar{h}$ obtained by correlations (30) and (33) for $S=15 \mathrm{~mm}$ is as high as $15.38 \%$ at $V_{a}=4 \mathrm{~m} /$ s and 14.78 at $V_{a}=5 \mathrm{~m} / \mathrm{s}$. However, their $\bar{h}$ difference is small for $S=5 \mathrm{~mm}$ and $V_{a}$ of $4-5 \mathrm{~m} / \mathrm{s}$. This means that even for $R i \approx 2.24 \times 10^{-5}$, the effect of natural convection at $S=15 \mathrm{~mm}$ is more significant than that of $S=5 \mathrm{~mm}$.

The velocity patterns and air temperature contours of the RNG and STD $k-\epsilon$ models with SWF are

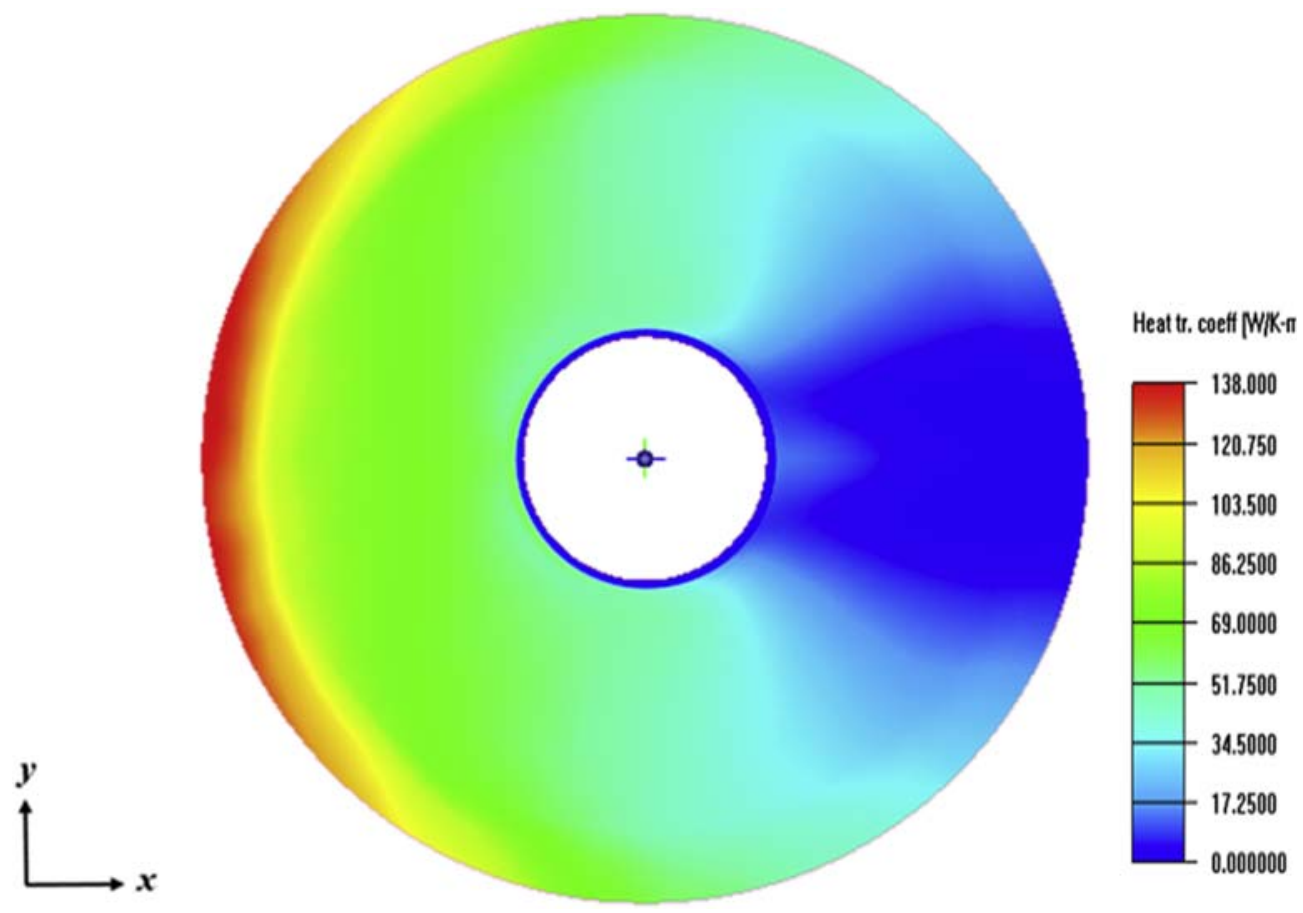

Fig. 6. Distribution of $h(r, \theta)$ with $V_{a}=4 \mathrm{~m} / \mathrm{s}$. 
similar. Therefore, the numerical results of the STD $k-\epsilon$ model and SWF are presented in Figs. 3-6. The velocity pattern of $S=5 \mathrm{~mm}$ on the plane of $z=S / 2$ is shown in Fig. 3 for $V_{a}$ of $4 \mathrm{~m} / \mathrm{s}$ and $5 \mathrm{~m} / \mathrm{s}$. It is seen that the velocity pattern of $S=5 \mathrm{~mm}$ in Fig. 3 agrees with Fig. 3b of Ref. [18] with $R e=7500$. The weaker vortices occurring downstream of the wake region with $R e=7500$ is dominant than $R e=4000$. The flow field is divided into three sections. It is found from Fig. 3 that the difference between the velocity patterns with $V_{a}$ of $4 \mathrm{~m} / \mathrm{s}$ and $5 \mathrm{~m} / \mathrm{s}$ is small. The airflow in the upstream region of the 1st section is nearly uniformly distributed at $V_{a}$ of $4 \mathrm{~m} / \mathrm{s}$ and $5 \mathrm{~m} / \mathrm{s}$. Air flows into the fins in the 2 nd section. The airflow entering the parallel fins hits the stagnation point on the tube and accelerates around the tube. The small low-speed region in front of the stagnation point can be observed from Fig. 3. After that, the airflow begins to separate from the separation point on the surface of the tube. The two vortices in the low-velocity wake region behind the tube are symmetrical and rotate in opposite directions. The wake region is longer for $V_{a}$ of $4 \mathrm{~m} / \mathrm{s}$ and $5 \mathrm{~m} / \mathrm{s}$ than for $V_{a}=3 \mathrm{~m} / \mathrm{s}$, as shown in Fig. 8 of Ref. [1]. This result is consistent with Fig. $2 \mathrm{~b}$ and $3 \mathrm{~b}$ of Ref. [18] with $R e=4000$ and 7500. A low-velocity airflow is observed in the 3rd section behind the fins.

Figure 4 shows the air temperature contours of $S=5 \mathrm{~mm}$ on the plane of $z=S / 2$ for $V_{a}$ of $4 \mathrm{~m} / \mathrm{s}$ and $5 \mathrm{~m} / \mathrm{s}$. It is observed that the air temperature contour between two adjacent fins shows a non-uniform distribution. As shown in the velocity pattern of Fig. 3, the difference between the air temperature contours with $V_{a}$ of $4 \mathrm{~m} / \mathrm{s}$ and $5 \mathrm{~m} / \mathrm{s}$ is also small.

The fin surface temperature contour of $S=5 \mathrm{~mm}$ is presented in Fig. 5 with $V_{a}=4 \mathrm{~m} / \mathrm{s}$. It is found from Fig. 10 of Ref. [1] and Fig. 5 that there are significant differences between the fin surface temperature contours with $V_{a}$ of $1 \mathrm{~m} / \mathrm{s}$ and $4 \mathrm{~m} / \mathrm{s}$. The high fin temperature region of $V_{a}=1 \mathrm{~m} / \mathrm{s}$ is much larger than that of $V_{a}=4 \mathrm{~m} / \mathrm{s}$.

Figure 6 presents the distribution of $h(r, \theta)$ with $V_{a}=4 \mathrm{~m} / \mathrm{s}$ and $S=5 \mathrm{~mm}$. It is found from Fig. 11 of Ref. [1] and Fig. 6 that there is a significant difference between $h(r, \theta)$ with $V_{a}=1 \mathrm{~m} / \mathrm{s}$ and $4 \mathrm{~m} / \mathrm{s}$. The region with lower $h(r, \theta)$ value of $V_{a}=1 \mathrm{~m} / \mathrm{s}$ is much larger than that of $V_{a}=4 \mathrm{~m} / \mathrm{s}$. At the leading edge of the fin, the $h(r, \theta)$ value of $V_{a}=4 \mathrm{~m} / \mathrm{s}$ is greater than that of $V_{a}=1 \mathrm{~m} / \mathrm{s}$.

It is found in Table 7 that $f$ with $V_{a}$ of $4-5 \mathrm{~m} / \mathrm{s}$ is less than 0.13 and increases with decreasing $V_{a}$. It has almost no variation with increasing $S$. This result is the same as that of Fig. 12 in Ref. [1] for $V_{a}$ of $1-3 \mathrm{~m} / \mathrm{s}$. The effect of $S$ on the value of $f$ decreases gradually as $V_{a}$ increases. This implies that $f$ has little change with increasing $S$ for $V_{a}$ of $4-5 \mathrm{~m} / \mathrm{s}$.

\section{Conclusions}

This study presents a hybrid method of CFD and IHCM in combination with $T_{k}^{m}$ to choose an appropriate $k-\epsilon$ model that can lead to more accurate results with $V_{a}$ of $4-5 \mathrm{~m} / \mathrm{s}$. The results indicate that the $\bar{h}$ value of the STD $k-\epsilon$ model with SWF is more consistent with the estimate of $\bar{h}$ than that of the REAL and RNG $k-\epsilon$ models, but the difference in $T_{k}^{n}$ between them is small. This implies that a comparison only for $T_{k}^{m}$ is not sufficient for selecting a suitable flow model and wall function. Both $T_{k}^{m}$ and the inverse result of $\bar{h}$ need to be compared. The $\bar{h}$ and $Q$ values of the STD $k-\epsilon$ model with SWF, $V_{a}=5 \mathrm{~m} / \mathrm{s}$ and $S=15 \mathrm{~mm}$ can be 1.14 and 1.04 times that of the RNG $k-\epsilon$ model and 0.48 and 0.42 times that of the REAL $k-\epsilon$ model, respectively. If the estimation of $\bar{h}$ is not accurate enough, it may affect the estimation of the $Q$ value. Therefore, it is important to select the appropriate flow model and wall function. The appropriate flow model and wall function need to be varied with $V_{a}$ in order to obtain more accurate numerical results. As far as we know, this discovery has not yet been proposed. This study has academic innovations and practical applications, such as energy-saving design of glass curtain buildings, ventilation design of hospital emergency rooms and operating rooms and high-performance heat exchangers, etc. For this study, the $R e$ ranges of the RNG and STD $k-\epsilon$ models are approximately from 570 to 4600 and from 6150 to 7,850 , respectively. The $\bar{h}$ and $y^{+}$values of the STD $k-\epsilon$ model are larger than those of the RNG $k-\epsilon$ model, but smaller than those of the REAL $k-\epsilon$ model. The $\bar{h}$ and $y^{+}$values of SWF are greater than those of EWT. The $y^{+}$results of RNG and STD $k-\epsilon$ models are in good agreement with those in Refs. [13,14,23]. However, the $y^{+}$results of the REAL $k-\epsilon$ model and SWF do not match those in Refs. $[10,13,14,23]$. The obtained $\bar{h}$ value is closer to the proposed correlation (30) with consideration of natural convection compared to the existing correlation (33). Thus, the correlation (30) has good reliability for engineering applications.

\section{Conflict of interest statement}

We expect our paper entitled "Investigation on Flow Models for Mixed Convection of Annular Finned Tube Heat Exchanger by the Inverse Method" to be published in the Journal of Marine 
Science and Technology. We declare that there is no actual or potential conflict of interest in this manuscript. There are no financial, personal or other relationships with other people or organizations that can inappropriately influence our work and its outcome.

I confirm that this manuscript has been approved by all named authors. No other person satisfies the criteria for authorship, but it is not listed. The order of the authors listed in the manuscript has been approved by all of us.

\section{Acknowledgments}

Part of this research finical supported by the National Taiwan Ocean University with Grant Number 109-105 is highly appreciated.

\section{References}

[1] Chen HT, Chang YL, Lin PY, Chui YJ, Chang JR. Numerical study of mixed convection heat transfer for vertical annular finned tube heat exchanger with experimental data and different tube diameters. Int J Heat Mass Tran 2018;118: 931-47.

[2] Chen HT, Chiu YJ, Liu CS, Chang JR. Numerical and experimental study of natural convection heat transfer characteristics for vertical annular finned tube heat exchanger. Int J Heat Mass Tran 2017;109:378-92.

[3] Chen HT, Hsieh YL, Chen PC, Lin YF, Liu KC. Numerical simulation of natural convection heat transfer for annular elliptical finned tube heat exchanger with experimental data. Int J Heat Mass Tran 2018;127:541-54.

[4] Chen HT, Hsu WL. Estimation of heat-transfer characteristics on a vertical annular circular fin of finned-tube heat exchangers in forced convection. Int J Heat Mass Tran 2008; 51:1920-32.

[5] Chen HT, Lu CH, Huang YS, Liu KC. Estimation of fluid flow and heat transfer characteristics for two-row plate-finned tube heat exchangers with experimental data. Heat Mass Tran 2016;52:969-79.

[6] Chen Ht, Ma WX, Lin PY. Natural convection of plate finned tube heat exchangers with two horizontal tubes in a chimney: experimental and numerical study. Int J Heat Mass Tran 2020;147C. 118948-118948-12.

[7] Fluid Dynamics Software. FLUENT 15, Lebanon, NH-USA. 2013.

[8] Gherasim I, Galanis N, Nguyen CT. Heat transfer and fluid flow in a plate heat exchanger. Part II: assessment of laminar and two-equation turbulent models. Int J Therm Sci 2011;50: 1499-511.
[9] Hsu WL. Estimation of heat transfer performance on the fin of annular-finned tube heat exchangers with measured temperature data. Taiwan: Department of Mechanical Engineering thesis, National Cheng Kung University; 2006.

[10] Hussain S, Oosthuizen PH, Kalendar A. Evaluation of various turbulence models for the prediction of the airflow and temperature distributions in atria. Energy Build 2012;48: 18-28.

[11] Mon MS, Gross U. Numerical study of fin-spacing effects in annular-finned tube heat exchangers. Int J Heat Mass Tran 2004;47:1953-64.

[12] Narayan S, Singh AK, Srivastava A. Interferometric study of natural convection heat transfer phenomena around array of heated cylinders. Int J Heat Mass Tran 2017;109:278-92.

[13] Nemati H, Moghimi M. Numerical study of flow over annular-finned tube heat exchangers by different turbulent models. CFD Lett 2014;6:101-12.

[14] Nemati H, Moghimi MA, Sapin P, Markides CN. Shape optimisation of air-cooled finned-tube heat exchangers. Int J Therm Sci 2020;150:106233.

[15] Nemati H, Moradaghay M, Moghimi MA, Meyer JP. Natural convection heat transfer over horizontal annular elliptical finned tubes. Int Commun Heat Mass Tran 2020;118:104823.

[16] Nemati H, Moradaghay M, Shekoohi SA, Moghimi MA, Meyer JP. Natural convection heat transfer from horizontal annular finned tubes based on modified Rayleigh Number. Int Commun Heat Mass Tran 2020;110:104370.

[17] Rincón-Casado A, Flor FJ Sánchez de la, Chacón Vera E, Ramos J Sánchez. New natural convection heat transfer correlations in enclosures for building performance simulation. Eng. Appl. Comput. Fluid Mech. 2017;11:340-56.

[18] Şabin B, Akkoca A, Özturk NA, Akilli H. Investigation of flow characteristics in a plate fin and tube heat exchanger model composed of single cylinder. Int J Heat Fluid Flow 2006;27: $522-30$.

[19] Salimipour E. A numerical study on the fluid flow and heat transfer from a horizontal circular cylinder under mixed convection. Int J Heat Mass Tran 2019;131:365-74.

[20] Senapati JR, Sukanta KD, Subhransu R. Numerical investigation of natural convection heat transfer from vertical cylinder with annular fin. Int J Therm Sci 2017;111:146-59.

[21] Xie GN, Wang QW, Sunden B. Parametric study and multiple correlations on air-side heat transfer and friction characteristics of fin-and-tube heat exchangers with large number of large-diameter tube rows. Appl Therm Eng 2009; 29:1-16.

[22] Yan W, Wu J, Yang S, Wang Y. Numerical investigation on characteristic flow regions for three staggered stationary circular cylinders. European J. Mech. B/Fluids 2016;60: $48-61$.

[23] Zhang Z, Zhang W, Zhai ZJ, Chen QY. Evaluation of various turbulence models in predicting airflow and turbulence in enclosed environments by CFD: Part 2-Comparison with experimental data from literature. HVAC R Res 2007;13: 871-86. 